\title{
Calibration of Four Nonlinear Failure Envelopes from Triaxial Test Data and Influence of Nonlinearity on Geotechnical Computations
}

\author{
Amaechi J. Anyaegbunam ${ }^{(}$, Fidelis 0. Okafor \\ Department of Civil Engineering, University of Nigeria, Nsukka, Nigeria \\ Email: anyaegbunam.amaechi@unn.edu.ng, fidelis.okafor@unn.edu.ng
}

How to cite this paper: Anyaegbunam, A.J. and Okafor, F.O. (2021) Calibration of Four Nonlinear Failure Envelopes from Triaxial Test Data and Influence of Nonlinearity on Geotechnical Computations. Geomaterials, 11, 42-57.

https://doi.org/10.4236/gm.2021.112003

Received: December 15, 2020

Accepted: April 5, 2021

Published: April 8, 2021

Copyright (อ 2021 by author(s) and Scientific Research Publishing Inc. This work is licensed under the Creative Commons Attribution International License (CC BY 4.0).

http://creativecommons.org/licenses/by/4.0/

\begin{abstract}
It is now recognized that many geomaterials have nonlinear failure envelopes. This non-linearity is most marked at lower stress levels, the failure envelope being of quasi-parabolic shape. It is not easy to calibrate these nonlinear failure envelopes from triaxial test data. Currently only the power-type failure envelope has been studied with an established formal procedure for its determination from triaxial test data. In this paper, a simplified procedure is evolved for the development of four different types of nonlinear envelopes. These are of invaluable assistance in the evaluation of true factors of safety in problems of slope stability and correct computation of lateral earth pressure and bearing capacity. The use of the Mohr-Coulomb failure envelopes leads to an overestimation of the factors of safety and other geotechnical quantities.
\end{abstract}

\section{Keywords}

Calibration of Nonlinear Failure Envelope, Triaxial Test Data, Modified Maksimovic Envelope, Power-Type Envelope, Polynomial-Type Envelope, Hoek-Brown Envelope, Standard Error of Estimate

\section{Introduction}

Comprehensive literature reviews on nonlinear envelopes can be found in [1] [2] and a repetition here will be superfluous. A nonlinear or curved failure envelope is shown in Figure 1. The friction angle $\phi$ is a continuously varying quantity. The non-linearity of failure envelopes is most marked at lower stress levels, the failure envelope being of quasi-parabolic shape [3]. The most commonly used nonlinear 


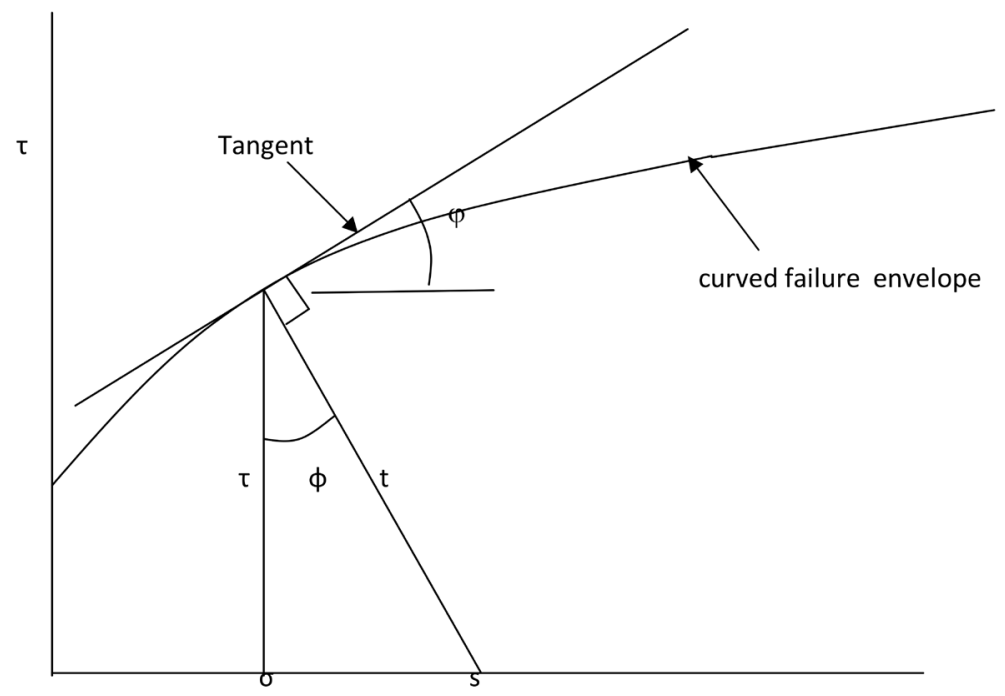

Figure 1. Curved failure envelope.

envelope is the power-type envelope $\tau=\tau_{o}\left(1+\frac{\sigma^{\prime}}{\sigma_{t}^{\prime}}\right)^{1 / m}$ or $\tau=\left(a+b \sigma^{\prime}\right)^{n}$ where $\tau=$ shear stress on failure arc; $\sigma^{\prime}=$ effective normal stress on failure arc $=\sigma-$ $u ; \sigma=$ total normal stress; $u=$ pore water pressure; $\sigma_{t}=$ tensile strength of geomaterial; $\tau_{o}=$ cohesion of geomaterial; $m$ is a constant. In the alternative representation $a, b$, and $n$ are constants with the case of $a=0$ being common and denotes a purely granular geomaterial. This had been used in several studies on slope stability [4] [5] [6]. Investigations carried out by Anyaegbunam [2] revealed that the power-type equation is a valid envelope for soil for all $n>0$ (except $n=$ $0.5)$ if

$$
a>\left[b^{2} n(1-2 n)\right]^{\frac{1}{2(1-n)}}
$$

prior to this discovery the power-type equation was affirmed to be a valid envelope for $n>0.5$ only [2] [5].

Additionally, it was discovered that the quadratic equation

$$
\tau=\left(a+b \sigma^{\prime}\right)^{0.5}
$$

can only be a legitimate failure envelope if

$$
a \geq \frac{b^{2}}{4}
$$

$a$ and $b$ are parameters in the equation of quadratic failure envelope.

The aims of this manuscript are to

1) Calibrate the modified Maksimovic nonlinear failure envelope from triaxial test data;

2) Develop a simplified procedure for calibrating the polynomial type failure envelope from triaxial test data;

3) Develop a simple methodology for calibrating the power-type failure envelope from triaxial test data; 
4) Produce a simpler procedure for calibrating the power-type failure envelope equivalent to the Hoek-Brown failure envelope using triaxial test data;

5) Compute the lateral earth pressure for a material with modified Maksimovic failure criterion;

6) Determine the factor of safety of a slope made of material with modified Maksimovic criterion;

7) Determine the factor of safety of a slope made of material with HoekBrown criterion.

This work has never been presented in the literature before. As had been mentioned real soil envelopes are nonlinear and the calibration of these nonlinear envelopes will help in determining the true response of soils. The accurate calibration of the Maksimovic failure envelope from triaxial test data has never been attempted before. The influences of nonlinearity on lateral earth pressure and factor of safety of slope with material made of modified Maksimovic law have never been attempted before and are quite difficult to implement.

\section{Methodology}

The calibration of a nonlinear failure envelope from triaxial test data is a problem of considerable difficulty [2] [7] [8]. To ease the calibration the formulas derived first by Balmer [9] come in handy.

They are:

$$
\begin{array}{r}
\sigma^{\prime}=\sigma_{3}^{\prime}+\frac{\sigma_{1}^{\prime}-\sigma_{3}^{\prime}}{1+\frac{\partial \sigma_{1}^{\prime}}{\partial \sigma_{3}^{\prime}}} \\
\tau=\frac{\sigma_{1}^{\prime}-\sigma_{3}^{\prime}}{1+\frac{\partial \sigma_{1}^{\prime}}{\partial \sigma_{3}^{\prime}}} \sqrt{\frac{\partial \sigma_{1}^{\prime}}{\partial \sigma_{3}^{\prime}}}
\end{array}
$$

where $\sigma^{\prime}$ and $\tau$ have their previous meanings, $\sigma_{1}^{\prime}=$ effective major principal stress at failure, $\sigma_{3}^{\prime}=$ effective minor principal stress at failure.

Given a set of experimental determined $\left(\sigma_{3}^{\prime}, \sigma_{1}^{\prime}\right)$ values then the normal stress and shear stress on the failure plane can be calculated from Equations (4) and (5) respectively.

It could be shown that

$$
\frac{\partial \sigma_{1}^{\prime}}{\partial \sigma_{3}^{\prime}}=N_{\varphi}=\frac{1+\sin \varphi^{\prime}}{1-\sin \varphi^{\prime}}
$$

where $\varphi^{\prime}=$ the effective instantaneous friction angle.

These authors deduced that the effective instantaneous cohesion $c^{\prime}$ is given by

$$
c^{\prime}=\frac{1}{2}\left[\sigma_{1}^{\prime} \sqrt{\frac{\partial \sigma_{3}^{\prime}}{\partial \sigma_{1}^{\prime}}}-\sigma_{3}^{\prime} \sqrt{\frac{\partial \sigma_{1}^{\prime}}{\partial \sigma_{3}^{\prime}}}\right]
$$

Equation (7) does not seem to exist in the literature. Fu and Liao (2010) seems to have derived the effective instantaneous cohesion for Hoek-Brown criterion that requires iteration to obtain. 


\subsection{Calibration of Modified Maksumovic Failure Envelope}

Maksimovic's [10] failure criterion has been determined to be excellent for rockfill.

According to Srbulov [11] this failure envelope provides the best fit to experimental data over a very wide stress range unlike the power-type envelopes that give low angle of friction at large normal stresses.

Maksimovic [10] proposed a hyperbolic failure law for rock-fills that can be expressed as

$$
\tau=\sigma^{\prime} \tan \left(a_{1}+\frac{1}{a_{2}+a_{3} \sigma^{\prime}}\right)
$$

which has three parameters that needs to be determined. $a_{1}, a_{2}$ and $a_{3}$ are related to the Maksimovic's parameters by $\varphi_{B}=a_{1}, \Delta \varphi=1 / a_{2}, P_{N}=a_{2} / a_{3}$. The determination of $a_{1}, a_{2}$ and $a_{3}$ is not straight forward at all. The parameters were determined for the experimental data presented in test No. O of Holtz and Gibbs [12] for a sample containing $20 \%$ gravel at a relative density of $50 \%$ shown in Table 1. It was discovered that the original Maksimovic [10] law Equation (8) does not provide an excellent match to the data.

Therefore a modified Makumovic hyperbolic law, that provided an improved match, was proposed namely

$$
\tau=\sigma^{\prime} \tan \left(a_{1}+\frac{\sigma^{\prime}}{a_{2}+a_{3} \sigma^{\prime}}\right)
$$

For a drained test on a granular material $\sigma^{\prime}=\sigma$. By using Equations (4) and (5) values of $\sigma$ and $\tau$ are computed in Table 1. Simple finite difference approximation has been used to compute values of $\partial \sigma_{1} / \partial \sigma_{3}$. These seem to be crude approximations but in practice have been found to give excellent results.

By substituting for the largest values of $\sigma$ and $\tau$ in Table 1, a relationship is derived between the constants, namely.

$$
a_{1}+\frac{\sigma_{m}}{a_{2}+a_{3} \sigma_{m}}=\arctan \left(\frac{\tau_{m}}{\sigma_{m}}\right)
$$

with $\sigma_{m}=1105.69$ and $\tau_{m}=814.85$.

Table 1. First two columns: Test data O from page 20 of Holtz and Gibbs (1952).

\begin{tabular}{ccccc}
\hline $\begin{array}{c}\sigma_{3} \\
\mathrm{KNm}^{-2}\end{array}$ & $\begin{array}{c}\sigma_{1} \\
\mathrm{KNm}^{-2}\end{array}$ & $\partial \sigma_{1} / \partial \sigma_{3}$ & $\begin{array}{c}\sigma \\
\mathrm{KNm}^{-2}\end{array}$ & $\begin{array}{c}\tau \\
\mathrm{KNm}^{-2}\end{array}$ \\
\hline 24.2 & 114.8 & 4.37 & 41.02 & 35.16 \\
44.9 & 204.90 & 5.14 & 70.94 & 59.07 \\
89.0 & 447.8 & 3.76 & 164.35 & 146.14 \\
174.6 & 692.8 & 3.63 & 286.49 & 213.21 \\
345.7 & 1380 & 3.90 & 556.77 & 416.84 \\
690.0 & 2703 & 3.84 & 1105.69 & 814.85 \\
\hline
\end{tabular}


To obtain the best values of $a_{2}$ and $a_{3}$ the method of least squares is used. To implement the least squares method Equation (9) should be expressed as

$$
\frac{\sigma}{\arctan \left(\frac{\tau}{\sigma}\right)-a_{1}}=y=a_{2}+a_{3} \sigma
$$

Applying the method of least squares it is obtained that

$$
\begin{gathered}
a_{2} N+a_{3} \sum \sigma_{i}=\sum y_{i} \\
a_{2} \sum \sigma_{i}+a_{3} \sum \sigma_{i}^{2}=\sum \sigma_{i} y_{i}
\end{gathered}
$$

where subscript $i$ will run from 1 to $N=$ number of data points which is 6 in this case. Equation (12) can be solved to obtain

$$
\begin{gathered}
a_{3}=\frac{N \sum \sigma y-\sum \sigma \sum y}{N \sum \sigma^{2}-\left(\sum \sigma\right)^{2}}, \\
a_{2}=\frac{\sum y-a_{3} \sum \sigma}{N}
\end{gathered}
$$

The best fit values of $a_{2}$ and $a_{3}$ should be obtained as follows: A certain value of $a_{1}$ near one is chosen and then values of $a_{2}$ and $a_{3}$ are calculated as shown above. Equation (10) is used to calculate another value of $a_{1}$. if the chosen and the calculated $a_{1}$ are equal then the correct solutions have been obtained. If they are different, then, another iteration should be done.

When the above routine is implemented it is obtained that the parameters for the modified Maksimovic failure law for the triaxial data given in Table 1 are

$$
a_{1}=1.0, a_{2}=-64.35, a_{3}=-2.6837 \text {. }
$$

The Mohr-Coulomb approximation to Table 1 is

$$
\tau=11.42+0.7269 \sigma
$$

with a SEE of 28.73. SEE $=$ the standard error of estimate calculated from

$$
\mathrm{SEE}=\sqrt{\frac{1}{N} \sum\left(\sigma_{1 \text { pred }}-\sigma_{1}\right)^{2}}
$$

The modified Maksumovic approximation to Table 1 is

$$
\tau=\sigma \tan \left(1.0-\frac{\sigma}{64.35+2.6837 \sigma}\right)
$$

with a slightly lower SEE of 28.04 and the envelope passing through $\tau=0$ as required. The modified Maksimovic failure envelope would give a better factor of safety when the stability of geomaterial of shallow depth is considered. In Figure 2 the $\mathrm{M}-\mathrm{C}$ and $\mathrm{M}-\mathrm{M}$ failure envelopes are compared. In Table 2 is shown the data for test W of Holtz and Gibbs [12] for a sample containing $20 \%$ gravel at a relative density of $70 \%$. The Mohr-Coulomb approximation to Table 2 is

$$
\tau=31.95+0.7542 \sigma
$$

with a SEE of 31.82 .

The modified Maksimovic approximation to Table 2 is 


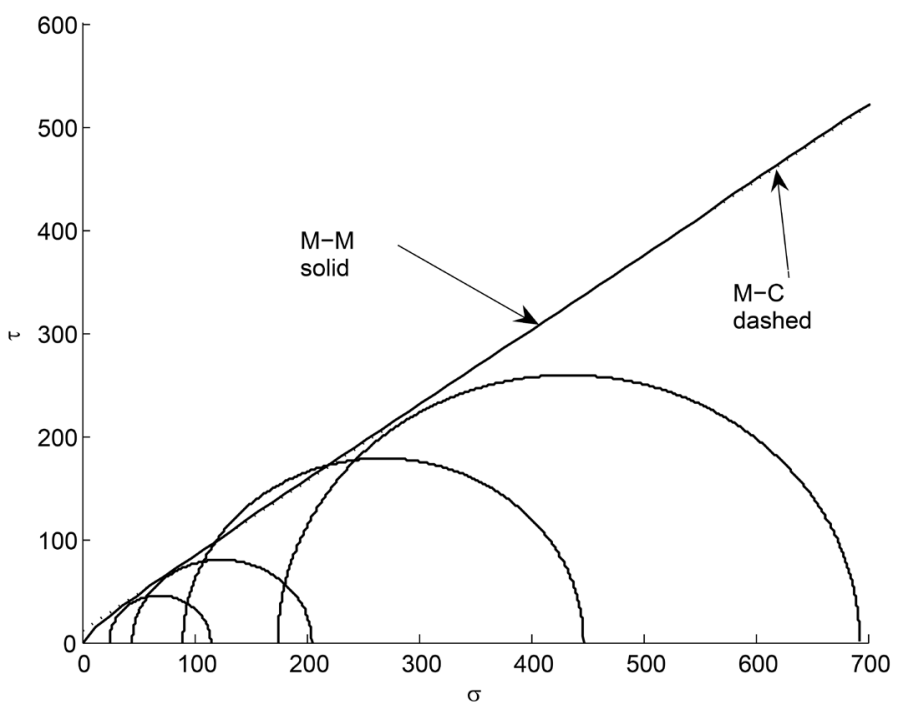

Figure 2. The $\mathrm{M}-\mathrm{C}$ and $\mathrm{M}-\mathrm{M}$ failure envelopes are compared wrt Mohr circles of Test data $\mathrm{O}$.

Table 2. Test data W from page 21 of Holtz and Gibbs (1952).

\begin{tabular}{cc}
$\begin{array}{c}\sigma_{3} \\
\mathrm{KNm}^{-2}\end{array}$ & $\begin{array}{c}\sigma_{1} \\
\mathrm{KNm}^{-2}\end{array}$ \\
22.8 & 192.5 \\
45.5 & 280.1 \\
88.3 & 523.7 \\
173.9 & 825.9 \\
347.0 & 1572 \\
691.0 & 2886 \\
\hline & \\
& \\
&
\end{tabular}

with a lower SEE of 23.78. This time around the difference is clear. The two envelopes are compared in Figure 3.

\subsection{Calibration of Polynomial Failure Envelope}

Yuanming et al. [13] derived a cubic polynomial $\sigma-\tau$ failure envelope for frozen sandy clay from $\sigma_{3}-\sigma_{1}$ triaxial test data shown in Table 3. In this case effective normal stress $=$ total normal stress. They calibrated the coefficients of the polynomial via a not really straightforward procedure. It is the purpose of this section to illustrate a much simpler procedure for doing the calibration.

Yuanming et al. [13]'s procedure was proceeded by a derivation by regression of a $\sigma_{1}-\sigma_{3}$ relation (Equation (16)) that enables an analytical determination of $\partial \sigma_{1} / \partial \sigma_{3}$ but these authors used a finite difference approximation for $\partial \sigma_{1} / \partial \sigma_{3}$.

$$
\sigma_{1}=\left(K_{o}\right)^{\sigma_{3} / P_{a t m}} \sigma_{c}\left(1+\frac{\sigma_{3}}{\sigma_{T}}\right)^{b_{o}}
$$




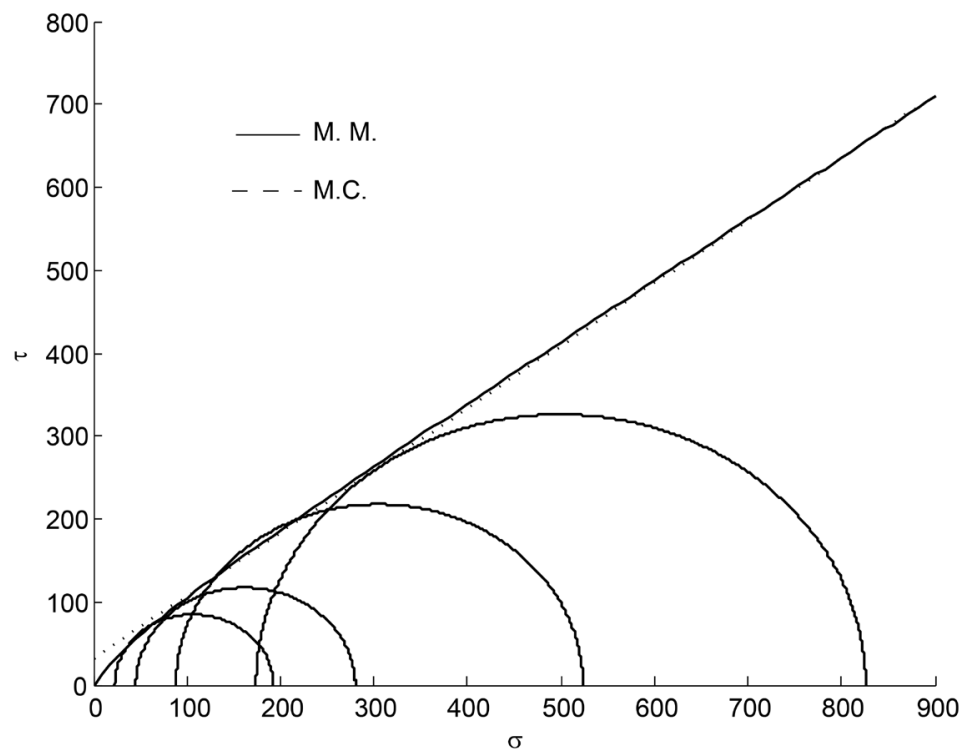

Figure 3. The $\mathrm{M}-\mathrm{C}$ and $\mathrm{M}-\mathrm{M}$ failure envelopes are compared wrt Mohr circles of Test data W.

Table 3. Test data for frozen sany clay at $-6^{\circ} \mathrm{C}$ from Yuanming et al. (2010) page 51.

\begin{tabular}{cccc}
\hline $\begin{array}{c}\sigma_{3} \\
\mathrm{MNm}^{-2}\end{array}$ & $\begin{array}{c}\sigma_{1} \\
\mathrm{MNm}^{-2}\end{array}$ & $\begin{array}{c}\sigma_{3} \\
\mathrm{MNm}^{-2}\end{array}$ & $\begin{array}{c}\sigma_{1} \\
\mathrm{MNm}^{-2}\end{array}$ \\
\hline 0.0 & 2.285 & 5.0 & 11.877 \\
0.3 & 3.289 & 6.0 & 12.924 \\
0.6 & 4.155 & 8.0 & 14.924 \\
0.8 & 4.726 & 10.0 & 17.161 \\
1.0 & 5.308 & 12.0 & 19.381 \\
2.0 & 7.392 & 14.0 & 20.795 \\
3.0 & 9.541 & 16.0 & 22.571 \\
4.0 & 11.140 & 18.0 & 24.953 \\
\hline
\end{tabular}

where $\sigma_{c}$ and $\sigma_{T}$ are the uni-axial compressive and tensile strengths of the specimen respectively.

$K_{o}$ and $b_{o}$ are experimental parameters. Equation (16) is not needed in this study.

Using Equations (4) and (5) on Table 3 a set of values of $\sigma$ and $\tau$ are obtained.

Let the cubic polynomial failure envelope be

$$
\tau=b_{1}+b_{2} \sigma+b_{3} \sigma^{2}+b_{4} \sigma^{3}
$$

Applying the method of least squares regression directly to this the following 4 equations are obtained

$$
\begin{gathered}
\sum \tau=N b_{1}+b_{2} \sum \sigma+b_{3} \sum \sigma^{2}+b_{4} \sum \sigma^{3} \\
\sum \sigma \tau=b_{1} \sum \sigma+b_{2} \sum \sigma^{2}+b_{3} \sum \sigma^{3}+b_{4} \sum \sigma^{4} \\
\sum \sigma^{2} \tau=b_{1} \sum \sigma^{2}+b_{2} \sum \sigma^{3}+b_{3} \sum \sigma^{4}+b_{4} \sum \sigma^{5}
\end{gathered}
$$




$$
\sum \sigma^{3} \tau=b_{1} \sum \sigma^{3}+b_{2} \sum \sigma^{4}+b_{3} \sum \sigma^{5}+b_{4} \sum \sigma^{6}
$$

where $N$ is number of data points and the subscripts have been deleted without loss of meaning.

When Equations (18a) to (18d) are solved for the constants $b_{1}$ to $b_{4}$ it is obtained that

$$
b_{1}=0.6549, b_{2}=0.6690, b_{3}=-0.04815, b_{4}=1.0773 \times 10^{-3}
$$

Yuanming et al. [13] obtained $b_{1}=0.6667, b_{2}=0.6290, b_{3}=-0.0423$, $b_{4}=0.90 \times 10^{-3}$

The two sets of constants can be seen to be approximately the same.

According to this paper the polynomial envelope is $\tau=0.6549+0.6690 \sigma-0.04815 \sigma^{2}+1.0773 \times 10^{-3} \sigma^{3}$

The standard error of estimate was determined to be SEE $=0.3727$. The MohrCoulomb envelope is determined to be $\tau=2.036+0.0969 \sigma$ with an SEE $=1.1870$. Thus, the Polynomial envelope provides a better fit to the experimental data. It is believed that the procedure used to do the calibration here is much more simpler and readily understood than the method of Yuanming et al.'s. A Q basic computer program [14] was used for doing all the relevant calculations and this program is available from the corresponding author on request. Figure 4 shows the Mohr circles of the experimental data of Table 3 and the associated M-C and polynomial failure envelopes.

\subsection{Calibration of the Power-Type Failure Envelope}

The power-type failure envelope takes the form $\tau=(a+b \sigma)^{n}$. A somehow complicated procedure for calibrating the power-type failure envelope has been given in Baker [1] and Anyaegbunam [2]. In Table 4 is shown experimental data lifted from Anyaegbunam [2].

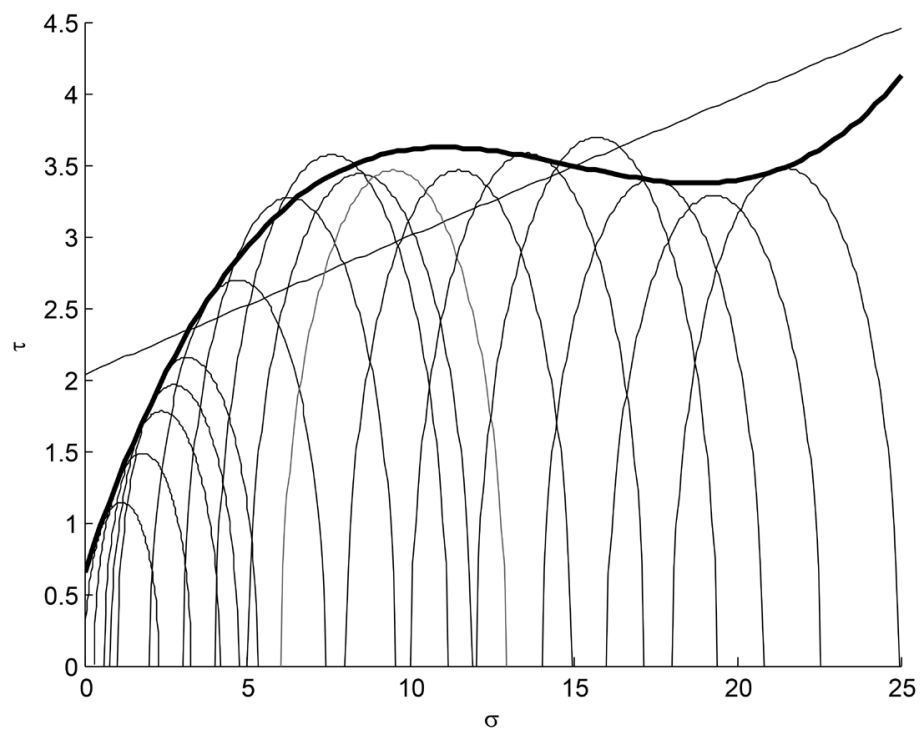

Figure 4. Mohr circles of the experimental data of Table 3 and the associated M-C and polynomial failure envelopes. 
Equations (4) and (5) are used to obtain the corresponding $\sigma$ and $\tau$ values at failure. The power-type equation is then expressed as

$$
a+b \sigma=\tau^{1 / n}
$$

By assuming several values of $n$ Equation (19) is subjected to least squares regression for each value of $n$. The value of $n$ that yields the minimum SEE is chosen as the correct failure envelope. This has been programmed in the afore mentioned QBASIC 4.5 program for the automatic determination of $n$, $a$ and $b$. For the data of Table 4 it is obtained that $\tau=(0.389+2.61 \sigma)^{0.748}$ with an SEE of 0.25 that is almost exact match to the experimental data. This agrees almost exactly with Anyaegbunam [2] that gave $\tau=(0.439+2.612 \sigma)^{0.748}$ using a more complicated procedure. The Mohr-Coulomb envelope for the data of Table 4 is $\tau=29.44+0.3812 \sigma$ that corresponds to $\varphi=\arctan (0.3812)=20.9^{\circ}$. Figure 5 shows the Mohr circles of the experimental data of Table 4 and the associated linear M-C and power-type failure envelopes.

\subsection{Calibration of the Power-Type Failure Envelope for the Hoek-Brown Criterion}

Hoek and Brown [15] presented a useful and practical equation for the insitu

Table 4. Consolidated undrained test data for a sample of laterite from Table 2 of Anyaegbunam (2015).

\begin{tabular}{cc}
$\sigma_{3}$ & $\begin{array}{c}\sigma_{1} \\
\mathrm{KNm}^{-2}\end{array}$ \\
69.0 & 225.8 \\
138 & 383.7 \\
276 & 664.4 \\
\hline
\end{tabular}

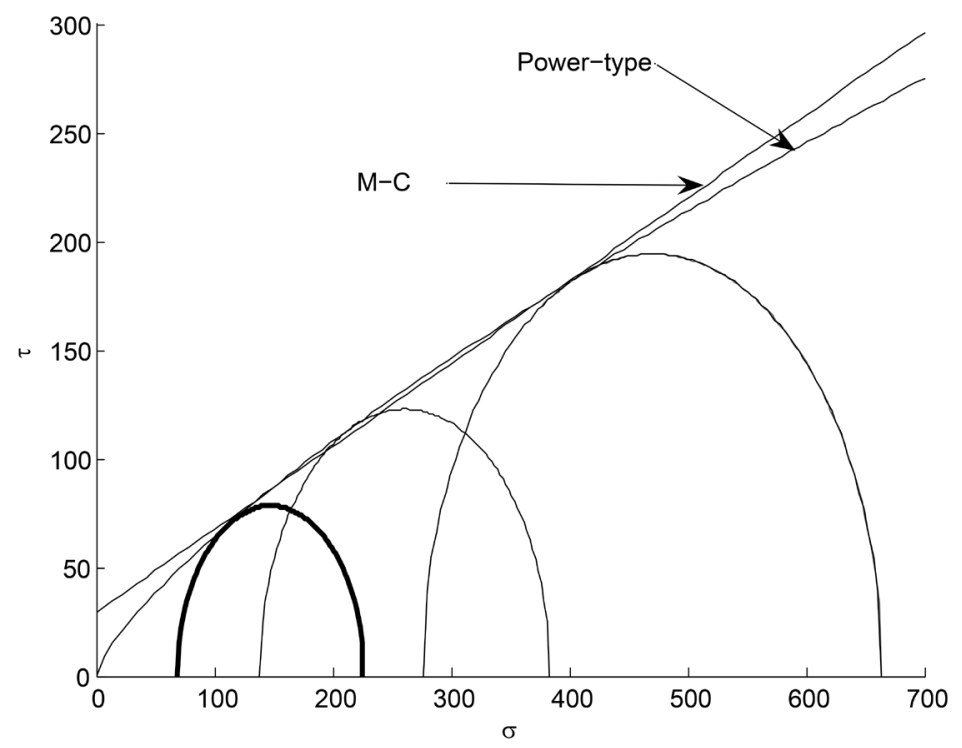

Figure 5. Mohr circles of the experimental data of Table 4 and the associated linear M-C and power-type failure envelopes. 
strength of rock mass. The 2002 version of this equation [16] (the modified HoekBrown criterion) is:

$$
\sigma_{1}=\sigma_{3}+\sigma_{c i}\left(\frac{m_{b} \sigma_{3}}{\sigma_{c i}}+s_{b}\right)^{\eta}
$$

where $m_{b}=m_{i} \exp \left(\frac{\mathrm{GSI}-100}{28-14 D}\right), \quad s_{b}=\exp \left(\frac{\mathrm{GSI}-100}{9-3 D}\right)$

$$
\eta=\frac{1}{2}+\frac{1}{6}[\exp (-\mathrm{GSI} / 15)-\exp (-20 / 3)]
$$

where $G S I$ is the Geological Strength Index, $D$ is the disturbance factor, $\sigma_{c i}=$ the compressive strength of the intact rock, $m_{i}$ is a material constant of the intact rock.

The Hoek-Brown criterion can be expressed simply as

$$
\sigma_{1}=\sigma_{3}+\left(\kappa \sigma_{3}+\beta\right)^{\eta}
$$

where $\kappa=m_{b} \sigma_{c i}^{\frac{1}{\eta}-1}$ and $\beta=s_{b} \sigma_{c i}^{\frac{1}{\eta}}$

$$
\text { Letting } F=\kappa \sigma_{3}+\beta \text { and } \operatorname{den}=\kappa \eta+2 F^{1-\eta}
$$

then it can be shown that

$$
\sigma=\sigma_{3}+\frac{F}{d e n} \text { and } \tau=\frac{F^{\frac{1+\eta}{2}}}{\operatorname{den}} \sqrt{\operatorname{den}-F^{1-\eta}}
$$

Equations (23a, b) are the exact parametric (implicit) equations of the Mohr envelope of the $\mathrm{H}-\mathrm{B}$ criterion. These equations with $\sigma_{3}$ as the paramaeter are not very much useful in practice because the value of $\tau$ are not easily calculated from that of $\sigma$, vice versa. Hence, it is necessary to determine a single equation connecting $\tau$ and $\sigma$.

The H-B criterion utilized herein have the following constants $\sigma_{c i}=40 \mathrm{MN} / \mathrm{m}^{2}$, $m_{i}=10, G S I=45, D=0.9$ with the rest calculated to be $m_{b}=0.281, \eta=0.508, s_{b}$ $=1.616 \times 10^{-4}$.

The Hoek-Brown equation cannot be directly used in slope stability analysis because it is defined in terms of principal stresses. Considerable difficulty is encountered when Hoek-Brown equation is used directly in strength-reduction finite element type of slope stability analysis [17] [18] hence it will useful to obtain its Mohr envelope for use in limit equilibrium analysis. Baker [1] shows that the power-type failure envelope $\tau=(a+b \sigma)^{n}$ provides an excellent fit to the HoekBrown criterion in the Mohr $(\sigma-\tau)$ plane. Therefore the Mohr envelope obtained in this section is of the power-type. Equation (21) has been used to derive Table 5 and Equations (23a and b) was used in the program to obtain values of $\sigma$ and $\tau$.

Figure 6 shows the Mohr circles of the H-B criterion and the associated Powertype envelope and M-C envelope. The derived power-type envelope has the equation $\tau=(353.3+22.343 \sigma)^{0.684}$ with a SEE of 6.63. The Mohr-Coulomb envelope has the equation $\tau=159.86+0.8014 \sigma$ or $\tau=159.86+\sigma \tan \left(38.71^{\circ}\right)$ with 
Table 5. Data for Hoek-Brown criterion specified in the text.

$\begin{array}{cc}\sigma_{3} & \begin{array}{c}\sigma_{1} \\ \mathrm{KNm}^{-2}\end{array} \\ \mathrm{KNm}^{-2}\end{array}$

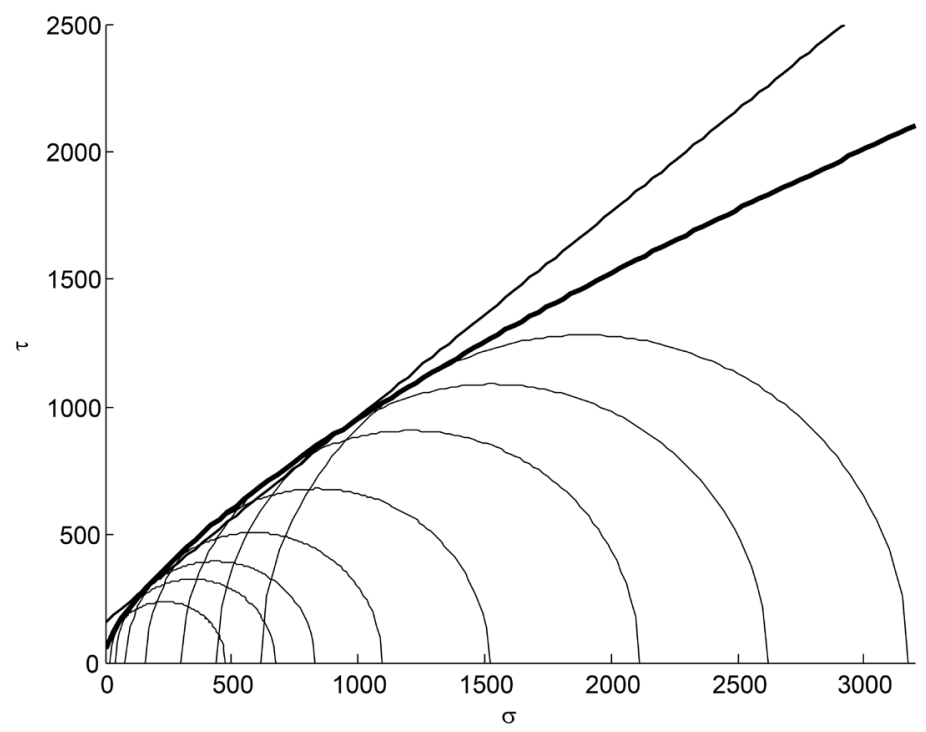

Figure 6. Mohr circles of the H-B criterion and comparison with linear M-C and nonlinear power-type failure envelopes.

a $\mathrm{SEE}=123.94$. The envelopes derived in Anyaegbunam [2] namely $\tau=(357.302+22.337 \sigma)^{0.684}$ with a SEE $=5.77$ and the M-C fit of $c=157.0 \mathrm{KN} / \mathrm{m}^{2}$ and $\varphi=38.7^{\circ}$ with a SEE $=131.77$ can be seen to be in excellent agreement. The method used in this paper can be seen to be much simpler and readily understood than Anyaegbunam [2]. Deng et al. [17] presented an approximate limit equilibrium technique for slope stability analysis using the Hoek-Brown criterion.

\section{Influence of Nonlinearity of Failure Envelope on Geotechnical Computations}

\subsection{Passive Pressure on a Smooth Wall Due to Soil with Modified Maksimovic Law Derived from Table 2}

This shall be illustrated for a $2.0 \mathrm{~m}$ smooth high wall that is a portion of a wall embedded in homogeneous soil of unit weight $\gamma=18 \mathrm{KN} / \mathrm{m}^{3}$. The vertical stress, which is the minimum principal stress, is given by $\sigma_{3}=\gamma z(i)$ where $z(i)=$ vertical 
distance from the ground surface. Assume that the wall height is divided into a number of divisions such that $\sigma_{3}$ can be denoted by $\sigma_{3}(i)$ and that the number of divisions is num. On the basis of a Mohr-Coulomb law the passive pressure at a given point is given by $\sigma_{1 M C}(i)=\sigma_{3}(i) N_{\varphi}+2 C \sqrt{N_{\varphi}}$. where $C$ and $\varphi$ are the M-C shear strength parameters and $N_{\varphi}=\tan ^{2}\left(\frac{\pi}{4}+\frac{\varphi}{2}\right) \cdot C=31.95 \mathrm{KN} / \mathrm{m}^{2}, \tan \varphi$ $=0.7542, a_{1}=1.0, a_{2}=-254.55, a_{3}=-2.7241$.

The pseudo code for evaluating the passive pressure according to the modified Maksimovic law will be as follows:

Dimension the variables

set $i=1$ : eps $=0.001$

450 compute $\sigma_{3}(\hat{i})$ : set $\sigma_{3}=\sigma_{3}(i)^{\prime} 450$ is line numbering in the code

$$
\text { compute } \sigma_{1 M C}(i) \text { : set } \sigma_{1 M C}=\sigma_{1 M C}(i)
$$

Let $\sigma_{n}=$ normal stress on the failure arc. Estimate $\sigma_{n}$ as $\sigma_{n 1}$.

$$
\sigma_{n 1}=0.45\left[\left(\sigma_{1 M C}+\sigma_{3}\right)-\left(\sigma_{1 M C}-\sigma_{3}\right) \sin \varphi_{M C}\right]
$$

where $\varphi_{M C}=\mathrm{M}-\mathrm{C}$ friction angle $\varphi$

$$
500 \tau=\sigma_{n 1} \tan \left(a_{1}+\frac{\sigma_{n 1}}{a_{2}+a_{3} \sigma_{n 1}}\right)
$$

Let $\operatorname{der}=\frac{\mathrm{d} \tau}{\mathrm{d} \sigma}$

$$
\begin{gathered}
\operatorname{der}=\frac{\tau}{\sigma_{n 1}}+\frac{a_{2} \sigma_{n 1}}{\left(a_{2}+a_{3} \sigma_{n 1}\right)^{2}}\left[1+\frac{\tau^{2}}{\sigma_{n 1}^{2}}\right] \\
t=\tau \sqrt{1+d e r^{2}}
\end{gathered}
$$

From Figure 1 it could be shown that

$$
\sigma_{n 2}=\sigma_{n}=\sigma_{3}+t-\sqrt{t^{2}-\tau^{2}}
$$

If $\mathrm{i}=$ num +1 then END

If $\left|\sigma_{n 2}-\sigma_{n 1}\right|>$ eps then $\sigma_{n 1}=\sigma_{n 2}$ : goto 500

If $\left|\sigma_{n 2}-\sigma_{n 1}\right| \leq e p s$ then $\sigma_{1}(i)=\sigma_{3}+2 t: i=i+1$ : goto 450

In Figure 7 are shown the Passive pressures calculated for M-C and M. M. material having test data $\mathrm{W}$.

The M-C soil has a passive force and moment of $401.4 \mathrm{KN} / \mathrm{m}$ and 353.1 $\mathrm{KNm} / \mathrm{m}$ at the base of the wall. The M.M. soil has a passive force and moment of $284.3 \mathrm{KN}$ and $203.5 \mathrm{KNm} / \mathrm{m}$ at the base of the wall which are $29.2 \%$ and $42.4 \%$ less than the M-C values respectively. This is usually the case for short walls that are less than $6.0 \mathrm{~m}$ in height.

\subsection{Factor of Safety of a Slope with Material Governed by a Modified Maksimovic Law and Comparison with M-C Equivalent}

It is proposed to determine the factor of safety of a $45^{\circ}$ homogeneous slope of 


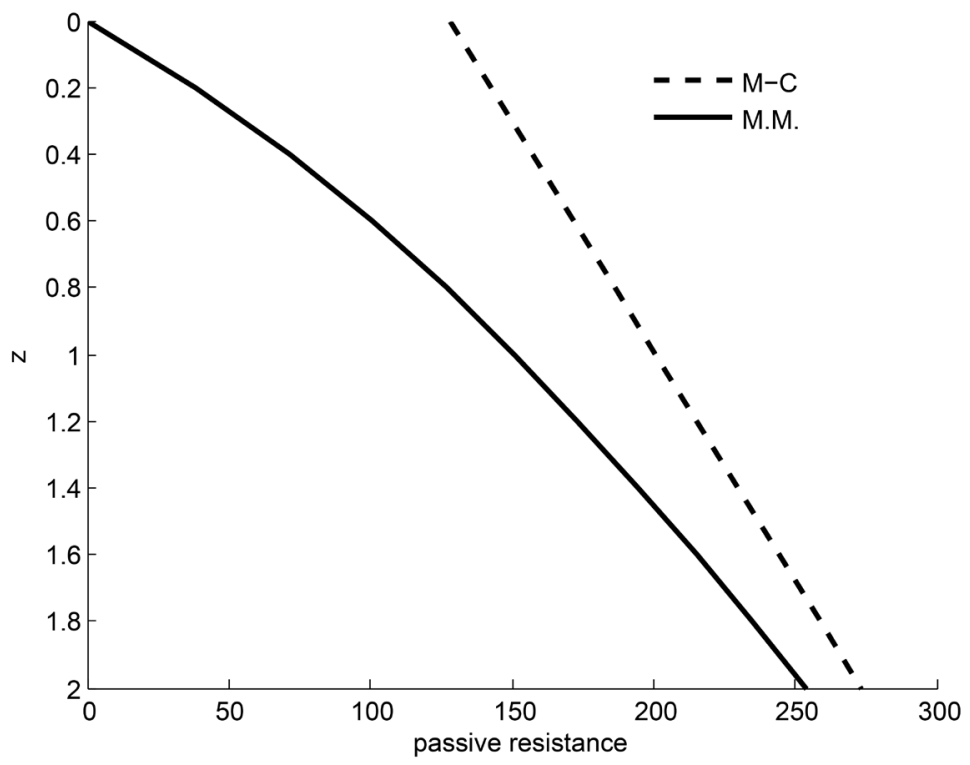

Figure 7. Passive Pressures of soil with M-C and M.M. envelopes for test data W.

height $10 \mathrm{~m}$ via a Maksimovic material model and $\mathrm{M}-\mathrm{C}$ material model using the Bishop simplified technique [19].

The material models were those derived from the triaxial data of Table 2 and are follows: For the M-C model: $C=31.95 \mathrm{KN} / \mathrm{m}^{2}, \phi=37.02^{\circ}$ and for the M. M. model: $a_{1}=1.0, a_{2}=-254.55, a_{3}=-2.7241$.

After the soil mass is divided into vertical slices the Bishop method for M-C material is given by

$$
F_{s}=\frac{1}{\sum \gamma h_{i} \sin \alpha_{i}} \sum \frac{c_{i}^{\prime}+\left(\gamma h_{i}-u_{i}\right) \tan \varphi^{\prime}}{\cos \alpha_{i}\left(1+\frac{\tan \alpha_{i} \tan \varphi^{\prime}}{F_{s}}\right)}
$$

where $F_{s}=$ factor of safety, $h_{i}=$ midheight of slice $i, \alpha_{i}=$ inclination of base of slice $i, u=$ pore pressure on base of slice $i$.

The Bishop method for modified Maksimovic (M.M.) material is given by

$$
F_{s}=\frac{1}{\sum \gamma h_{i} \sin \alpha_{i}} \sum \frac{\sigma_{i}^{\prime}}{\cos \alpha_{i}} \tan \left[a_{1}+\frac{\sigma_{i}^{\prime}}{a_{2}+a_{3} \sigma_{i}^{\prime}}\right]
$$

where $\sigma_{i}^{\prime}$ is obtained for each slice from the equation

$$
\sigma_{i}^{\prime}+\tan \alpha_{i} \frac{\sigma_{i}^{\prime}}{F_{s}} \tan \left[a_{1}+\frac{\sigma_{i}^{\prime}}{a_{2}+a_{3} \sigma_{i}^{\prime}}\right]-\left(\gamma h_{i}-u_{i}\right)=0
$$

The factor of safety $F_{s}$ is determined by assuming an initial value of $F_{s}$ and calculating $\sigma_{i}^{\prime}$ from Equation (27). Thereafter $\sigma_{i}^{\prime}$ are substituted into Equation (26) to re-calculate $F_{s}$. The calculation of $F_{s}$ using the Bishop method on a M.M. material model does not exist in the literature.

Using the $\mathrm{M}-\mathrm{C}$ material model and 10 slices, the following results are obtained: $F_{s}=2.40$ with the critical toe circle of radius $14.75 \mathrm{~m}$ centered at $(-0.64$, $14.74)$ with a central angle of $68.8^{\circ}$. Using the M.M. material model the $F_{s}=1.64$ 
Table 6. Comparison of $\mathrm{F}_{s}$ via Deng et al.'s H-B LEM and this paper's H-B power-type LEM Bishop method.

\begin{tabular}{cccc}
\hline $\mathrm{H}$ & $\boldsymbol{\beta}$ & Deng's method & This paper's method \\
\hline 15 & $30^{\circ}$ & 2.570 & 2.586 \\
15 & $45^{\circ}$ & 1.905 & 1.903 \\
15 & $60^{\circ}$ & 1.482 & 1.453 \\
\hline
\end{tabular}

with the critical toe circle of radius $16.87 \mathrm{~m}$ centered at $(-4.46,16.27)$ with a central angle of $52.8^{\circ}$. The use of the M.M. material model is seen to have a strong influence on the calculated factor of safety which is seen to be smaller.

Unfortunately the M.M. law has not been used for stability calculations by other authors and comparison of the results herein cannot be compared with previous results.

\subsection{Factor of Safety of Slope Using Deng et al.'s Approximate LEM with Hoek-Brown Parameters Compared with This Paper's Rigorous Hoek-Brown Method}

Deng et al. [17] developed an approximate limit equilibrium method (LEM) with Hoek-Brown parameters for determining the factor of safety of a rock slope.

The H-B parameters of the rock slope are $D=0, G S I=100, m_{i}=10, \sigma_{c i}=140$ $\mathrm{KNm}^{-2}, \alpha=\eta=0.5 . m_{b}$ and $s_{b}$ are calculated from Equation (20). The rock unit weight is $\gamma=23 \mathrm{KN} / \mathrm{m}^{3}$.

$$
\begin{gathered}
\text { Also, } \sigma_{c m}=\sigma_{c i} \frac{\left[m_{b}+4 s_{b}-\alpha\left(m_{b}-8 s_{b}\right)\right]\left[\frac{m_{b}}{4}+s_{b}\right]^{\alpha-1}}{2(1+\alpha)(2+\alpha)} \\
\sigma_{3 \max }=0.72 \sigma_{c m}\left(\frac{\sigma_{c m}}{\gamma H}\right)^{-0.91}
\end{gathered}
$$

$\sigma_{3}$ values are listed from values of 0 to $\sigma_{3 \max }$ and the $\mathrm{H}-\mathrm{B}$ relation is used to calculate corresponding values of $\sigma_{1}$. From these the power-type equivalent to this Hoek-Brown law is deduced by section (3.4) to be $\tau=(134.53+14.431 \sigma)^{0.643}$. The derived SEE $=1.26$. In Table 6 is shown the results of factors of safety of slope stability obtained via the two methods. The F.S. for a slope using the power-type envelope was obtained using a modification of the method of Charles and Soares [20]. The F.S. of a slope using Deng et al.'s method was obtained using Equation (18) of their paper. The calculated factors of safety can be seen to be close except when $\beta>60^{\circ}$ when they differ appreciably as Deng et al. discovered.

\section{Conclusion}

Four Mohr failure envelopes have been presented and the methods of for deriving them from experimental triaxial test data have been explained. The method for computing the passive resistance for granular soil with M.M. (modified Mak- 
simovic) envelope is presented. In addition, the influence of a M.M. envelope on the factor of safety of slope is presented and it is shown that the use of a M.M. material model results in a significant reduction in the calculated factor of safety. Also, it is shown that the factors of safety of rock slope obtained by this paper's power-type approximation and LEM are close to Deng et al.'s factors of safety using $\mathrm{H}-\mathrm{B}$ approximation and LEM. A computer program written in QBASIC version 4.5 for doing all the calibrations has been developed by the authors and is available on request from the corresponding author. This program is a useful contribution to geotechnical engineering practice.

\section{Acknowledgements}

The authors wish to thank the University of Nigeria for the payment of the 2019 earned allowances to its staff that helped in funding this research.

\section{Conflicts of Interest}

The authors declare no conflicts of interest regarding the publication of this paper.

\section{References}

[1] Baker, R. (2004) Non-Linear Strength Envelopes Based on Triaxial Test Data. Journal of Geotechnical \& Geoenvironmental Engineering, 130, 498-506. https://doi.org/10.1061/(ASCE)1090-0241(2004)130:5(498)

[2] Anyaegbunam, A.J. (2015) Nonlinear Power-Type Failure Laws for Geomaterials: Synthesis from Triaxial Data, Properties and Applications. International Journal of Geomechanics, 15, Article ID: 04014036. https://doi.org/10.1061/(ASCE)GM.1943-5622.0000348

[3] Collins, I.F., Gunn, C.I.M., Pender, M.J. and Wang, Y. (1988) Slope Stability Analyses for Materials with a Nonlinear Failure Envelope. International Journal for $\mathrm{Nu}$ merical and Analytical Methods in Geomechanics, 12, 533-550. https://doi.org/10.1002/nag.1610120507

[4] Zhang, X.-J. and Chen, W.-F. (1987) Stability Analysis of Slopes with General Nonlinear Failure Criterion. International Journal for Numerical and Analytical Methods in Geomechanics, 11, 33-50. https://doi.org/10.1002/nag.1610110104

[5] Jiang, J.-C., Baker, R. and Yamagami, T. (2003) The Effect of Strength Envelope Nonlinearity on Slope Stability Computations. The Canadian Geotechnical Journal, 40, 308-325. https://doi.org/10.1139/t02-111

[6] Li, X. (2007) Finite Element Analysis of Slope Stability Using a Nonlinear Failure Criterion. Computers and Geotechnics, 34, 127-136. https://doi.org/10.1016/j.compgeo.2006.11.005

[7] Ucar, R. (1986) Determination of Shear Failure Envelope in Rock Masses. Journal of Geotechnical Engineering, 112, 303-315. https://doi.org/10.1061/(ASCE)0733-9410(1986)112:3(303)

[8] Sheorey, P.R. (1997) Empirical Rock Failure Criteria. A.A. Balkema, Rotterdam.

[9] Balmer, G. (1952) A General Analytical Solution for Mohr's Envelope. Proceedings of American Society of Test Materials, Vol. 52, 1260-1271.

[10] Maksimovic, M. (1989) Nonlinear Failure Envelope for Soils. Journal of Geotech- 
nical \& Geoenvironmental Engineering, 115, 581-586.

https://doi.org/10.1061/(ASCE)0733-9410(1989)115:4(581)

[11] Srbulov, M. (1997) On the Influence of Soil Strength Brittleness and Nonlinearity on Slope Stability. Computers and Geotechnics, 20, 95-104.

https://doi.org/10.1016/S0266-352X(96)00014-6

[12] Holtz, W.G. and Gibbs, H.J. (1956) Shear Strength of Pervious Gravelly Soils. Journal of the Soil Mechanics and Foundations Division, 82, 1-22. https://doi.org/10.1061/JSFEAQ.0000004

[13] Lai, Y.M., et al. (2010) Stress-Strain Relationships and Nonlinear Mohr Strength Criteria of Frozen Sandy Clay. Soils and Foundations, 50, 45-53.

https://doi.org/10.3208/sandf.50.45

[14] QBASIC 4.5 [Computer Software]. Redmond, WA, Microsoft.

[15] Hoek, E. and Brown, E.T. (1980) Empirical Strength Criterion for Rock Masses. Journal of Geotechnical \& Geoenvironmental Engineering, 106, 1013-1035.

https://doi.org/10.1061/AJGEB6.0001029

[16] Hammah, R.E., Curran, J.H., Yacoub, T.E. and Corkum, B. (2004) Stability Analysis of Rock Slopes Using the Finite Element Method. In: Schubert, W., Ed., Proceedings ISRM Regional Symposium EUROCK 2004 and 53rd Geomechanics Colloquy: Rock Engineering - Theory and Practice, International Society for Rock Mechanics, Lisbon, 783-788.

[17] Deng, D.P., Zhao, L.H. and Li, L. (2017) Limit Equilibrium Analysis for Rock Slope Stability Using Hoek-Brown Strength Criterion. Journal of Central South University, 24, 2154-2163. https://doi.org/10.1007/s11771-017-3624-4

[18] Fu, W. and Liao, Y. (2010) Non-Linear Shear Strength Reduction Technique in Slope Stability Calculation. Computers and Geotechnics, 37, 288-298. https://doi.org/10.1016/j.compgeo.2009.11.002

[19] Bishop, A.W. (1955) The Use of the Slip Circle in the Stability Analysis of Slopes. Géotechnique, 5, 7-17. https://doi.org/10.1680/geot.1955.5.1.7

[20] Charles, J.A. and Soares, M.M. (1984) The Stability of Slopes in Soils with Nonlinear Failure Envelopes. Canadian Geotechnical Journal, 21, 397-406.

https://doi.org/10.1139/t84-044 